\title{
Buffered memory: a hypothesis for the maintenance of functional, virus-specific CD8(+) T cells during cytomegalovirus infection.
}

Christopher M Snyder

Thomas Jefferson University

Follow this and additional works at: https://jdc.jefferson.edu/mifp

Part of the Medical Genetics Commons, Medical Immunology Commons, and the Medical Microbiology Commons

Let us know how access to this document benefits you

\section{Recommended Citation}

Snyder, Christopher M, "Buffered memory: a hypothesis for the maintenance of functional, virusspecific CD8(+) T cells during cytomegalovirus infection." (2011). Department of Microbiology and Immunology Faculty Papers. Paper 27.

https://jdc.jefferson.edu/mifp/27

This Article is brought to you for free and open access by the Jefferson Digital Commons. The Jefferson Digital Commons is a service of Thomas Jefferson University's Center for Teaching and Learning (CTL). The Commons is a showcase for Jefferson books and journals, peer-reviewed scholarly publications, unique historical collections from the University archives, and teaching tools. The Jefferson Digital Commons allows researchers and interested readers anywhere in the world to learn about and keep up to date with Jefferson scholarship. This article has been accepted for inclusion in Department of Microbiology and Immunology Faculty Papers by an authorized administrator of the Jefferson Digital Commons. For more information, please contact: JeffersonDigitalCommons@jefferson.edu. 
Immunologic Research And later published as: Buffered Memory: A hypothesis for the

5 maintenance of functional, virus-specific CD8+ T cells during cytomegalovirus infection.

7 Volume 51, Issue 2-3, December 2011, Pages 195- 
2 correspondence should be addressed to:

3 Department of Microbiology and Immunology, Thomas Jefferson University,

4233 S. 10th Street, BLSB Philadelphia PA, 19107

$5 \quad$ christopher.snyder@jefferson.edu,ph (215)-503-2543

6

7 Key words: murine cytomegalovirus, CD8+ T cell, memory inflation 


\section{Abstract:}

2 Chronic infections have been a major topic of investigation in recent years, but

3 the mechanisms that dictate whether or not a pathogen is successfully controlled

4 are incompletely understood. Cytomegalovirus (CMV) is a herpesvirus that

5 establishes a persistent infection in the majority of people in the world. Like other

6 herpesviruses, CMV is well controlled by an effective immune response and

7 induces little, if any, pathology in healthy individuals. However, controlling CMV

8 requires continuous immune surveillance and thus, CMV is a significant cause of

9 morbidity and death in immune compromised individuals. T cells in particular play

10 an important role in controlling CMV and both CD4+ and CD8+ CMV-specific T

11 cells are essential. These virus-specific T cells persist in exceptionally large

12 numbers during the infection, traffic into peripheral tissues and remain functional,

13 facts that make CMV an attractive vaccine vector for driving "CMV-like" $\mathrm{T}$ cell

14 responses against recombinant antigens of choice. However, the mechanisms by

15 which these T cells persist and differentiate while remaining functional are still

16 poorly understood and we have no means to promote their development in

17 immune compromised patients at risk for CMV disease. In this review, I will

18 briefly summarize our current knowledge of CMV-specific CD8+ T cells and

19 propose a mechanism that may explain their maintenance and preservation of

20 function during chronic infection.

21

22 Introduction: CMV latency and persistence 
1 Herpesviruses are large DNA viruses that evolved an estimated 180 to 220

2 million years ago and have been co-speciating with their hosts ever since [1],

3 resulting in a very finely tuned host-pathogen balance. Herpesviruses establish

4 persistent or latent infections and induce little, if any, pathology in healthy hosts,

5 thanks largely to sustained, functional immune responses. Cytomegalovirus

6 (CMV) is a ubiquitous member of the $\beta$-subfamily of herpesviruses. Primary CMV

7 infection typically occurs in childhood and is usually asymptomatic. After an

8 active phase during which infectious virions are shed, CMV is controlled to levels

9 that are at, or just below what is readily detectable. Despite substantial

10 investigation, CMV remains an enigmatic virus and much of the viral behavior

11 during the persistent/latent phase of infection remains a mystery. However,

12 persistent CMV infection is characterized by periods of viral reactivation and

13 shedding, and constant immune surveillance is vital to keep CMV under control.

15 Our understanding of the ongoing host-virus interaction that keeps CMV in check

16 is somewhat limited, in part because the cells harboring latent virus or presenting

17 viral antigen during persistent infection are still incompletely defined. Several

18 groups have identified latent human CMV (HCMV) in hematopoietic progenitor

19 cells or monocyte/macrophages (reviewed in [2]). However, work in mice

20 suggests that hematopoietic cells are only part of the picture. Murine CMV

21 (MCMV) is a natural mouse pathogen and the homologue of human CMV. Both

22 viruses induce similar infections and are controlled by similar immune responses.

23 Like HCMV, MCMV is also thought to establish latency in macrophages [3, 4]. 
1 However, after primary infection, MCMV viral DNA is cleared from the blood and

2 bone marrow but not the salivary glands, lungs or spleen [5] suggesting that

3 relatively little of the MCMV genome is maintained by blood-derived cells.

4 Moreover, in the spleens of chronically infected mice, viral reactivation in explant

5 cultures was most easily detected in the stromal fraction and was unaffected by

6 depletion of lymphocytes or MHC class II bearing cells [6], again suggesting a

7 major non-hematopoietic site of MCMV latency. Endothelial cells have been

8 identified as one such non-hematopoietic site of MCMV latency $[3,7]$ and it is

9 likely that non-hematopoietic sites of latency, particularly endothelial cells [8], are

10 important for HCMV as well. Additional sites of latency are also likely and the

11 degree to which each contributes to the maintenance of the latent viral pool will

12 be of significant interest.

14 Initially, there was substantial debate about whether CMV remained persistent

15 (i.e. constantly replicating at a low rate) or achieved true molecular latency at late

16 times post infection. While it is now generally accepted that CMV achieves true

17 molecular latency, it is also evident that the virus undergoes frequent

18 reactivation. Landmark experiments by Reddehase and colleagues showed that

19 despite ubiquitous viral DNA in the lungs of mice infected for 12 months, viral

20 RNA in the lungs was expressed in a patchwork pattern [9]. These data

21 suggested that viral reactivation occurred frequently, but only in a fraction of

22 infected cells at any given time. This group further showed that the patchwork

23 viral reactivation rarely led to the production of infectious virions [10]. In order to 
1 replicate, $\mathrm{CMV}$ transcribes its genes in an ordered cascade that begins with

2 immediate early (IE) genes followed by early (E) genes, DNA replication and

3 ultimately late $(L)$ genes that encode structural virion components. While the

4 patchwork expression of viral RNA in the lungs frequently included IE genes, as

5 shown previously, $E$ and $L$ genes were undetectable [10]. Similarly, infectious

6 virus was undetectable even with techniques that allowed detection of as few as

75 viral genomes [11]. Importantly, this group has also shown that MCMV-specific

8 CD8+ T cells block the progression of viral gene expression during reactivation

9 [12], indicating that immune surveillance contributes to the suppression of virion

10 production. These data show that CMV is present in a latent state and that

11 reactivation occurs frequently, but also that reactivation is usually aborted or

12 blocked prior to complete gene expression and production of virions.

14 Overall, the data suggest that CMV is constantly pressuring the immune system.

15 Compromising the immune system of CMV-infected individuals frequently results

16 in disseminated viral replication and substantial morbidity and death. Many arms

17 of the immune system contribute to viral control. Interferons, natural killer (NK)

18 cells, CD4+ T cells, CD8+ $T$ cells and antibody all play a recognized role in

19 controlling viral replication and spread [13]. Once latency is established, viral

20 reactivation seems to be largely controlled by the combined efforts of NK cells,

21 CD4+ and CD8+ T cells [14], though the specific contributions of these cells

22 remain more obscure. CD4+ T cells play a direct role in controlling viral

23 replication, likely by cytokine secretion or cytotoxicity [15-18]. In addition, CMV- 
1 specific CD4+ T cells may help CMV-specific CD8+ T cell responses [19-21].

2 CD8+ T cells for their part, have been shown to directly limit viral reactivation in

3 healthy mice [12] and can control viral replication in otherwise

4 immunocompromised humans and mice [22-24].

6 Memory Inflation: The CD8+ T cell response to CMV.

$7 \quad$ CMV-specific CD4+ and CD8+ T cells are present in staggering numbers during

8 the persistent infection in healthy people, comprising approximately $5 \%$ of all

9 circulating T cells and $10 \%$ of all memory T cells in the average adult host [25].

10 Strikingly, the frequencies of virus-specific CD8+ T cells increase over the course

11 of infection. This slow increase in the numbers or frequency of virus-specific

12 CD8+ T cells has been referred to as "memory inflation" and occurs in both

13 MCMV infected mice and HCMV infected people [26-33]. For the purposes of this

14 review, "memory inflation" is used in its most basic sense: to describe the

15 increasing numbers and frequency of CMV-specific CD8+ T cells over time. The

16 general assumption has been that these "inflationary" CD8+ T cell populations

17 are the direct result of ongoing viral activity. How these inflationary cells develop,

18 how frequently they are stimulated and how they respond to each stimulation

19 event remain open questions.

20

21 Memory inflation of virus-specific CD8+ T cells is, in many ways, unique to CMV

22 infection. It is generally agreed that the majority of inflationary CMV-specific T

23 cells resemble extensively differentiated, but functional effector cells. This has 
1 been investigated in both HCMV-infected people and MCMV-infected mice by

2 many laboratories [26, 28, 30, 32-45] and an interesting picture has emerged.

3 Most CMV-specific T cells express perforin and granzyme, they can kill antigen-

4 bearing target cells, and they can secrete IFN- $\gamma$ and TNF- $\alpha$, but only very little IL-

5 2. However, many of these cells bear phenotypic hallmarks of repeated antigen

6 stimulation. For example, most CMV-specific T cells lack expression of the co-

7 stimulatory molecules CD27 and CD28, as well as L-selectin (CD62L) and the

8 chemokine receptor CCR7 that allow for access to lymph nodes. Likewise, many

9 CMV-specific effectors have reduced expression of the receptors for IL-7 and IL-

10 15, cytokines important for homeostatic maintenance of memory T cells. In

11 humans, many of these $\mathrm{T}$ cells express the memory-marker CD45RO, but a

12 subset, considered to be the most terminally differentiated, express CD45RA, a

13 marker typically expressed by naïve T cells. CMV-specific CD8+ T cells with this

14 phenotype have short telomeres, indicating an extensive proliferative history [46].

15 Importantly, the frequency of these cells directly correlates with the amount of

16 virus at the peak of infection [37].

18 In addition to the phenotype described above, CMV-specific inflationary T cells

19 also upregulate a variety of NK-associated receptors including the activating

20 receptor NKG2D and the inhibitory receptors NKG2A and KLRG-1 along with

21 CD57 and CD85j in humans [31, 33, 47-50]. Expression of KLRG-1 in particular

22 is associated with repeated antigen stimulation [51], although it is also

23 upregulated by CD8 T cells during acute viral infections [52]. It is unclear how 
1 CMV-specific T cells with this phenotype will be affected by this combination of

2 reduced co-stimulatory molecule expression and increased inhibitory molecule

3 expression. One possibility is that they have a restricted or decreased

4 proliferative capacity after stimulation. Indeed, expression of the inhibitory

5 molecules CD57 and KLRG-1, has been associated with reduced or absent

6 proliferative potential (senescence) [47, 48, 53-56]. However, CMV-specific

7 inflationary T cells do not appear to be senescent in healthy adult hosts. Although

8 CMV-specific T cells undergo relatively little proliferation at steady state during

9 chronic CMV infection [20, 28, 32, 38, 57, 58], T cells with the phenotype

10 described can be induced to divide by the correct combination of stimuli. In

11 particular, stimulating inflationary $\mathrm{T}$ cells through both the $\mathrm{T}$ cell receptor (TCR)

12 and common $\gamma$-chain cytokine receptors results in cell division as does the

13 simultaneous stimulation of both the TCR and 4-1BB (CD137, a member of the

14 TNF-receptor family) [42, 43, 59]. Likewise, MCMV-specific inflationary cells

15 divide after MCMV challenge in an adoptive transfer model [33]. It seems likely

16 that additional co-stimulatory pathways will also push these inflationary $T$ cells

17 into cell cycle. Thus, CMV-specific inflationary T cells seem to be repeatedly

18 stimulated, but functional effectors during chronic infection, at least in healthy

19 adults, but require specific combinations of stimuli to enter cell cycle. For the

20 remainder of this article, I will refer to CMV-specific inflationary cells with this

21 phenotype as effector $T$ cells ( $T_{E F F}$ ) to distinguish them from small populations

22 that retain a more memory-like phenotype (described below). 


\section{$1 \quad$ CMV-specific "memory-like" $T$ cells}

2 The accumulation of the CMV-specific T cells with the phenotype described

3 above is contrasted by a persistence of other T cells with a more memory-like

4 phenotype. Many of these memory-phenotype cells do not recognize the same

5 antigens as the $T_{E F F}$ cells that undergo memory inflation. CMV infection in both

6 mice and humans elicits T cells specific for a broad array of antigens $[25,60]$ and

7 many of these $T$ cells contract after acute infection and persist at low levels

8 thereafter [30, 32, 33]. These "non-inflationary" T cells tend to develop a more

9 classical memory phenotype (i.e. retention of co-stimulatory molecules and

10 cytokine receptors and an absence of inhibitory receptors), suggesting that they

11 may not be repeatedly stimulated despite the persistent infection. Recent data

12 have suggested that these non-inflationary $T$ cells may recognize peptides that

13 depend on the immunoproteasome for production [61]. Since non-professional

14 antigen presenting cells do not constitutively express the immunoproteasome,

15 these peptides may be rarely produced during chronic infection. However, there

16 are also small subsets of cells that retain a memory-like phenotype despite

17 sharing peptide specificity with large numbers of $T_{E F F}$ cells, which can not be

18 explained by limited peptide presentation.

20 Using the mouse model of MCMV infection in C57BL/6 mice, we and others have

21 begun dissecting the array of CD8+ T cell responses elicited by MCMV over time.

22 We typically analyze T cells specific for 5 different viral antigens: M45, M57,

$23 \mathrm{~m} 139, \mathrm{M} 38$ and IE3. Schematics of the kinetics of these T cell responses are 
1 illustrated in Figure 1a. T cells specific for M45 and M57 contract after acute

2 infection and develop a memory-like phenotype at late times post infection,

3 illustrated here by high levels of CD127 (IL-7R $\alpha$ ) expression and little KLRG-1

4 expression (Figure $1 \mathrm{~b}$ and [30,33]). These are prototypical examples of non-

5 inflationary T cells. In contrast, inflationary T cells specific for the viral antigens

6 m139, M38 and IE3 accumulate after MCMV infection, each with distinct kinetics

7 (Figure 1a). These cells mostly develop a $T_{\text {EFF }}$ phenotype, illustrated here by a

8 downregulation of CD127 and expression of KLRG-1 (Figure 1b). However, there

9 is always a small subset of inflationary T cells (m139-, M38- or IE3-specific) that

10 retain CD127 expression and do not upregulate KLRG-1 (upper left quadrants in

11 Figure 1b). These memory-phenotype inflationary cells generally comprise less

12 than $10-15 \%$ of the total antigen-specific pool (Figure 1c) and there is only a little

13 data hinting at their functional capacity: HCMV-specific T cells that are memory-

14 phenotype tended to expand better than $\mathrm{T}_{\mathrm{EFF}} \mathrm{HCMV}$-specific $\mathrm{T}$ cells after

15 allogeneic stem cell transplantation [62] and our data [33] implied that MCMV-

16 specific CD8+ T cells with a memory-phenotype expanded more robustly than

$17 T_{E F F}$ cells with the same specificities after viral challenge. If memory is defined by

18 the speed and magnitude of recall responses, these data suggest that the

19 memory-phenotype cells are more "memory-like" than their $T_{\text {EFF }}$ counterparts,

20 although more work is needed to define these differences.

22 The mechanisms dictating whether individual T cells with a given specificity will

23 remain memory-like or differentiate into effectors during chronic infection are 
1 currently unclear. Analyses of HCMV-specific CD8+ T cells indicate that

2 individual $\mathrm{T}$ cell clones can be found within both $\mathrm{T}_{\mathrm{EFF}}$ and memory-like

3 populations [63], indicating that segregation or selection into either subset is not

4 dependent on a particular $\mathrm{T}$ cell receptor. Are $\mathrm{T}_{\mathrm{EFF}}$ cells, as their phenotype may

5 suggest, the only cells that respond to viral antigens during chronic infection? If

6 memory-like cells are stimulated, what is their fate? Likewise, what is the fate of

$7 \quad T_{\text {EFF }}$ cells stimulated during chronic infection? More precise measurements of the

8 development, maintenance, behavior and functional potential of these two

9 inflationary $T$ cell subpopulations are needed to begin addressing these

10 questions. However, for the remainder of this article, I would like to consider the

11 idea that both of these populations work in tandem to enable the maintenance of

12 life-long, functional CMV-specific immunity.

\section{Short or long-lived CMV-specific CD8+ T cells.}

15 Given the absence of substantial proliferation within CMV-specific inflationary

16 populations $[20,28,32,38,57,58]$, there are two basic hypotheses describing

17 the homeostasis and persistence of inflationary $T_{\text {EFF }}$ cells. The first suggests that

18 CMV-specific T cells are long-lived, resting effectors (discussed in [64]). This

19 model states that CMV-specific T cells are functional effectors that will circulate

20 for long periods of time and suppress reactivating or replicating virus when it is

21 encountered. These $T_{\text {EFF }}$ cells may not undergo much or any cell division after

22 each stimulation event unless the conditions are ideal (e.g. appropriate co-

23 stimulation and/or cytokine signals). Supporting this model is the evidence that 
1 individual CMV-specific clones of cells can persist for several years [63, 65]. In

2 addition, in humans, CD45RA+CMV-specific T cells only emerge after acute

3 infection has been resolved [45]. As restimulation of these cells in vitro promotes

4 re-expression of CD45RO [44], these data may imply that the CD45RA+ subset

5 of CMV-specific T cells are resting and have not been recently stimulated. Thus,

6 in this model, a long half-life and only occasional cell division, driven by a specific

7 combination of stimuli, maintain the population.

9 The alternate hypothesis states that CMV-specific T cell populations are

10 extremely dynamic, comprising mostly short-lived effector cells that are

11 continually replaced as they die, thus maintaining the population as a whole

12 (Figure 2). We proposed this model because inflationary MCMV-specific T cells

13 from the spleens of chronically infected mice failed to sustain themselves after

14 adoptive transfer into either naïve or chronically infected animals [33]. In the

15 presence of virus, CMV-specific T cells underwent some cell division, but not

16 enough to maintain their numbers, and the transferred populations slowly

17 decayed with a half-life of approximately 1 to 2 months. Thus, we proposed that

18 the majority of inflationary T cells were actually short-lived effectors, similar in

19 phenotype $\left(C D 127^{\text {low }}, K L R G-1^{\text {pos }}\right.$, Figure $\left.1 \mathrm{~b}\right)$ and function to short-lived effector

20 cells elicited by acutely cleared infections [66]. Consistent with this model, it was

21 shown that $C D 127^{\text {low }}\left(T_{\text {EFF }}\right)$ inflationary $T$ cells express less of the anti-apoptotic

22 molecule $\mathrm{Bcl}-2$ than cells with the same specificity that retained CD127

23 expression (memory-like cells) [32]. This could imply that $\mathrm{T}_{\mathrm{EFF}}$ inflationary cells 
1 are more prone to apoptosis than memory-like inflationary $T$ cells. Moreover,

2 recent evidence has shown that HCMV elicited CD45RA+, CD4+ T cells (the

3 most differentiated) are susceptible to apoptosis after antigen-stimulation in vitro

4 [67]. Although still unclear, it is interesting to speculate that both CD4+ and CD8+

$5 \quad$ CMV-specific T cell populations may be dominated by short-lived populations.

7 Short-lived $\mathrm{T}_{\mathrm{EFF}}$ cells might be repeatedly produced by more memory-like $\mathbf{T}$

8 cells.

9 In our model, there must be a continuous source of new short-lived effector cells

10 to replace those that die in order for the inflationary populations to be maintained

11 (Figure 2). Our data showed that naïve T cells can be recruited during chronic

12 infection to provide some new effector cells [33] and a similar model was

13 proposed to account for maintenance of murine polyomavirus-specific T cells [68,

14 69]. However, we further showed that insufficient numbers of $T$ cells were

15 recruited from the naïve pool to account for maintenance of the MCMV-specific

16 inflationary populations [33]. Instead our data suggested that a population of $T$

17 cells produced early in the infection could maintain the inflationary $T$ cell pool.

18 Thus, $T$ cells transferred only 7 days after infection into infection matched

19 recipients could provide long-term maintenance of the donor populations. We

20 interpreted these data to suggest that some sort of memory or memory-like

21 population was generated during primary infection and then repeatedly

22 stimulated to produce new short-lived $T_{\text {EFF }}$ cells via clonal expansion (Figure 2).

23 As long as the production rate of new $T_{\text {EFF }}$ cells exceeded their rate of loss, the 
1 result would be memory inflation. Once the production rate of $T_{E F F}$ cells equaled

2 the rate of loss, the population would persist at an elevated, but stable level.

4 Since clones of memory-like cells would be responsible for repeatedly producing

$5 T_{\text {EFF }}$ cells, this model is consistent with the fact that individual HCMV-specific

6 CD8+ $T$ cell clones are found in both $T_{E F F}$ and memory-like subsets [63]. In

7 addition, this model could explain the maintenance of certain T cell clones over

8 many years: a small pool of memory-like cells would produce $T_{\text {EFF }}$ cells with a

9 limited clonal composition and individual clones would develop into effectors

10 repeatedly over time. If some clones were present at higher frequencies in the

11 memory-like pool, or possessed T cell receptors within an ideal avidity range,

12 these would undoubtedly be selected into the $T_{\text {EFF }}$ pool more frequently. Thus,

13 competition between the memory clones could explain the selection of some but

14 not all clones over time. Interestingly, a study by Day et. al. [65] showed that

15 within a few weeks of primary HCMV infection, a relatively small number of $\mathrm{T}$ cell

16 clones were selected into the CD8+ T cell population specific for a given peptide

17 and that the relative frequency of individual clones fluctuated with time. Although

18 fluctuations in clonal frequency from time point to time point might represent

19 more or less comprehensive blood sampling, such fluctuations would also be

20 predicted by a model in which different clonal expansions contribute to the

21 maintenance of the whole population. 
1 If memory-like T cells are responsible for clonal expansions that support a

2 circulating $T_{\text {EFF }}$ pool, where might such memory clones reside? In our

3 experiments [33], CMV-specific populations from the spleen were unable to

4 sustain themselves. Thus, any memory population in the spleen was either

5 incapable of supporting memory inflation after adoptive transfer, or was

6 transferred in insufficient numbers to support the donor antigen-specific pool.

7 Alternative locations such as the bone marrow or lymph nodes may harbor

8 increased numbers of the relevant cell population. Interestingly, while the

9 frequency of memory-phenotype inflationary cells was greater in the spleen and

10 bone marrow relative to the blood, there was little or no difference between the

11 bone marrow and the spleen (Figure $1 \mathrm{~b}$ and $\mathrm{c}$ ). It remains formally possible that

12 bone marrow resident memory cells are functionally distinct from spleen resident

13 cells however, requiring further experiments to test the functional properties of

14 these subsets.

16 It must be noted however, that because we used adoptive transfer experiments

17 to test the persistence of MCMV-specific T cells, there is an alternative

18 explanation for our results: CMV-specific T cells (either $\mathrm{T}_{\mathrm{EFF}}$ cells, memory-like

19 cells or both) may require a specific niche in which to survive. Thus, when we

20 transferred MCMV-specific T cells into chronically infected mice, the niches in the

21 host may have been filled with the host's own MCMV-specific T cells, thereby

22 excluding the donor cells. It is possible that this niche is not filled early

23 (explaining our ability to transfer self-sustaining populations at day 7 post 
1 infection) but could fill over time with memory inflation. Studies specifically

2 designed to investigate the survival and engraftment of transfused MCMV-

3 specific T cells are required.

4

5 CMV-specific T cells for adoptive therapy:

6 The difference between these two models (short- vs. long-lived inflationary T

7 cells) may have a significant impact on the development of adoptive

8 immunotherapy for immune compromised patients. There are no therapies for

9 boosting CMV-specific T cell responses in immune compromised patients.

10 Therefore, several groups have been working to develop methods for the

11 isolation and passive transfusion of CMV-specific T cells from healthy donors into

12 immune compromised recipients at risk for CMV disease (recently reviewed in

13 [70]). Typically, CMV-specific T cells have been isolated based on their ability to

14 secrete IFN- $\gamma$ after antigen-stimulation although in some cases, T cell clones or

15 directly sorted, tetramer-binding T cells have been used. These procedures have

16 yielded some promising results, but are still experimental and costly and

17 questions still remain about how to ensure persistence of effective donor T cells

18 after transfusion. Indeed, transfused T cells can only provide protection for as

19 long as they survive. If the majority of isolated T cells are short-lived and

20 continuously replaced, the challenge may be to transfer a self-sustaining

21 population that can control CMV over long periods of time. Interestingly, the

22 Riddell group, pioneers of this therapeutic approach to mitigate CMV infection

$23[19,24]$, have shown using a non-human primate model of CMV infection, that $T$ 
1 cell clones derived from "central memory" (CD28+, CD95+) but not more

2 differentiated "effector memory" (CD28-, CD95+) subsets persist after adoptive

3 immunotherapy [71]. These data support the idea that CMV-specific $T_{\text {EFF }}$ cells

4 may be less effective than more memory-like populations over long periods of

5 time. If we can develop an understanding of precisely how CMV-specific

6 populations are generated and sustained, it may become possible to transfuse

7 more protective or longer lasting CMV-specific populations or even to promote

8 these cells directly in immune compromised patients.

10 T cell exhaustion: A paradigm for several chronic infections.

11 Aside from the homeostasis of CMV-specific $\mathrm{T}_{\mathrm{EFF}}$ and memory-like $\mathrm{T}$ cells, their

12 maintenance of effector function is also remarkable. The development of

13 dysfunctional CD8+ T cells, generally called T cell "exhaustion", occurs during

14 several other chronic infections including Hepatitis C, Hepatitis B, HIV, and in the

15 mouse models of chronic lymphocytic choriomeningitis virus (LCMV) infection

16 (recently reviewed in [72]). Exhaustion during these infections is typically

17 characterized by a progressive loss in the ability of CD8+ T cells to produce

18 cytokines (first IL-2, then TNF- $\alpha$ and eventually IFN- $\gamma$ ), as well as to survive,

19 proliferate and kill targets. However, there is little evidence of such exhaustion

20 occurring during CMV infection except in immune compromised patients with

21 high titers of replicating CMV $[73,74]$. Indeed, exhaustion appears to be a

22 defined molecular program induced in T cells by some chronic infections [75] and

23 gene expression profiles of HCMV-specific T cells do not conform to this 
1 molecular signature [38]. Notably, during chronic CMV infection in healthy

2 humans and mice, CMV-specific T cells do not upregulate PD-1 [20, 38], one

3 inhibitory molecule that is strongly associated with antigen-driven $\mathrm{T}$ cell

4 exhaustion. Indeed, even in the absence of CD4+ T cell help, an environment

5 that accelerates and exacerbates CD8+ T cell exhaustion after chronic LCMV

6 infection [76, 77], only relatively mild CD8+ T cell dysfunction develops after

$7 \quad M C M V$ infection, despite the additional fact that MCMV is never fully controlled in

8 the absence of CD4+ T cells $[20,21]$.

10 One explanation for the lack of exhaustion during CMV infection is that CMV is a

11 "smoldering" infection $[72,76]$, with ongoing viral replication never reaching

12 levels that can drive T cell dysfunction in healthy hosts. In line with this, T cell

13 exhaustion in mice infected with LCMV-clone 13, a virus that replicates to high

14 titers, is associated with continuous antigen-driven T cell proliferation [78] while

15 CMV-specific T cells undergo relatively little proliferation during chronic infection

16 in both humans and mice $[20,28,32,38,57,58]$. As mentioned above, this is not

17 because $\mathrm{CMV}$-specific $\mathrm{T}$ cells are unable to proliferate. The correct combination

18 of stimuli will drive even $T_{E F F}$ phenotype cells into cell cycle $[42,43,59]$. Thus,

19 either CMV-specific T cells rarely encounter antigen, or they are frequently

20 stimulated by antigen, but rarely driven into cell cycle. Perhaps the expression of

21 inhibitory molecules by $T_{\text {EFF }}$ cells and their dependence on cytokines and/or

22 certain co-stimulatory signals limits cell division and thus, exhaustion. This may

23 be especially true since many $T_{\mathrm{EFF}}$ cells can be found within non-lymphoid 
1 organs [26, 28, 32], where they may be exposed to much of the antigen

2 produced by reactivating virus $[5,79]$, but not the cytokines or co-stimulatory

3 molecules necessary for cell division [42, 43, 59]. Consistent with this idea,

4 continuous MCMV replication in CD4+ T cell deficient mice was necessary to

5 support the size of inflationary CD8+ T cell populations [21], but did not result in

6 markedly increased proliferation by inflationary CD8+ T cells [20]. Thus, even in

7 this scenario, where it was clear that MCMV-specific CD8+ T cells responded to

8 antigen from a continuously replicating virus, they still underwent relatively limited

9 cell division. Therefore, proliferation may be a poor indicator of how frequently

10 MCMV-specific T cells encounter antigen and it is possible that the $T_{E F F}$ state,

11 with its specific requirements for entering the cell cycle, may itself prevent the

12 development of exhaustion, regardless of how frequently these cells are

13 stimulated.

15 Buffered Memory: A hypothesis to explain the preservation of functional

16 memory CD8+ $\mathrm{T}$ cells during persistent $\mathrm{CMV}$ infection

17 Regardless of how the CMV-specific $T_{E F F}$ cells remain functional, an additional

18 mystery is the preservation of functional memory-like cells during chronic MCMV

19 infection. Perhaps the $T_{\mathrm{EFF}}$ cells, by recognizing the majority of viral antigen and

20 controlling the majority of viral gene expression, simply prevent the memory-like

21 T cells from being overstimulated during persistent CMV infection. If $T_{E F F}$ cells

22 suppress viral reactivation in the tissue effectively, their presence should limit the

23 antigen burden placed on the more memory-like cells, thus preventing memory- 
1 like cells from responding to all but a fraction of viral antigen (Figure 3). In this

2 way, perhaps the $T_{\text {EFF }}$ cells act as a buffer for the memory-like cells and only

3 occasional "leaks" of viral antigen or perhaps antigen expression in a particular

4 environment (e.g. a specific cell type or organ) stimulate the memory-like T cells.

5 Perhaps, without $T_{\text {EFF }}$ cells CMV-specific memory cells might otherwise be driven

6 to undergo terminal differentiation or become exhausted while occasional

7 stimulation might act more like a vaccine boost, inducing the memory-like cells to

8 undergo clonal expansion and produce more $T_{\text {EFF }}$ cells, thereby adding to and

9 supporting the whole CMV-specific inflationary population. Thus, the immune

10 system may not be capable of accumulating or sustaining $T_{\text {EFF }}$ cells without a

11 memory population to produce more $T_{E F F}$ cells as needed (especially if $T_{E F F}$ cells

12 are short-lived), while the memory population might not persist in a functional

13 state without being shielded from the majority of antigen.

\section{Concluding Remarks:}

16 The model presented here is obviously only relevant if the CMV-specific memory-

17 like cells play some role in the development or maintenance of memory inflation.

18 To investigate the models proposed here, it will be important to determine the

19 effect of stimulating both $\mathrm{T}_{\mathrm{EFF}}$ and memory-like CMV-specific $\mathrm{T}$ cells during

20 chronic infection. Are the memory-like cells depleted over time or can they

21 sustain themselves through repeated rounds of stimulation? Are memory-like

22 cells stimulated at a different rate than $T_{E F F}$ cells? Are $T_{E F F}$ cells short- or long-

23 lived and can they persist in a functional state in the absence of memory-like 
1 cells with the same specificity (e.g. when transferred into immune compromised

2 hosts infected with MCMV)? The answers to these questions will hinge on how

3 much antigen stimulation occurs during chronic infection, how it impacts the

4 virus-specific $T$ cells and where that stimulation takes place for both $T_{E F F}$ and

5 memory-like cells. Recent experiments have begun to shed light on some of the

6 details, suggesting that memory inflation depends on antigen-presentation by

7 non-hematopoietic cells [80] and that direct presentation of antigen by infected

8 cells is sufficient for memory-inflation [81]. Together, these observations fit nicely

9 with the evidence that inflationary T cells recognize peptides that can be

10 produced by non-professional antigen presenting cells lacking

11 immunoproteasomes [61]. In addition, our recent data showed that a limited

12 subset of cells infected by MCMV in the first round of infection were sufficient to

13 stimulate memory inflation (Snyder et. al, PLoS Pathogens, in press). It will be

14 interesting to determine which cells are responsible for presenting viral antigens

15 and whether they stimulate T cell division, recruitment or differentiation, or rather

16 prolong the survival of $T_{E F F}$ cells so that the rate of $T_{E F F}$ cell production exceeds

17 the rate of loss, resulting in accumulation.

19 Aside from the basic goals of understanding the complex relationship between

$20 \mathrm{CMV}$ and its host, the answers to the questions outlined in this review may be

21 relevant for promoting sustainable CMV-specific immunity in patients at risk for

22 CMV disease. Whether or not the models described here are ultimately

23 supported by the data, it will be important to determine how the homeostasis of 
1 CMV-specific T cells is influenced by factors such as pro- and anti-inflammatory

2 cytokines, co-stimulatory and inhibitory receptors, and different types of antigen-

3 presenting cells. Finally, it will be interesting, as we learn more, to determine

4 whether the mechanisms that support life-long immunity to CMV are broadly

5 applicable to other chronic infections within the herpesvirus family or by unrelated

6 pathogens.

8 Acknowledgements:

9 The data presented in Figure $1 \mathrm{~b}$ and $\mathrm{c}$ was collected by Elizabeth L. Bonnett

\section{References}

12

13
1. McGeoch DJ, Cook S, Dolan A, Jamieson FE, Telford EA: Molecular phylogeny and evolutionary timescale for the family of mammalian herpesviruses. J Mol Biol. 1995;247(3):443-58

2. Sinclair J, Sissons P: Latency and reactivation of human cytomegalovirus. Journal of General Virology. 2006;87(Pt 7):1763-79

3. Koffron AJ, Hummel M, Patterson BK, Yan S, Kaufman DB, Fryer JP et al.: Cellular localization of latent murine cytomegalovirus. J Virol. 1998;72(1):95-103

4. Pollock JL, Presti RM, Paetzold S, Virgin HWt: Latent murine cytomegalovirus infection in macrophages. Virology. 1997;227(1):168-79

5. Balthesen M, Messerle M, Reddehase MJ: Lungs are a major organ site of cytomegalovirus latency and recurrence. J Virol. 1993;67(9):5360-6

6. Mercer JA, Wiley CA, Spector DH: Pathogenesis of murine cytomegalovirus infection: identification of infected cells in the spleen during acute and latent infections. J Virol. 1988;62(3):987-97

7. Seckert CK, Renzaho A, Tervo HM, Krause C, Deegen P, Kuhnapfel B et al.: Liver sinusoidal endothelial cells are a site of murine cytomegalovirus latency and reactivation. J Virol. 2009;83(17):8869-84

8. Jarvis MA, Nelson JA: Human cytomegalovirus tropism for endothelial cells: not all endothelial cells are created equal. J Virol. 2007;81(5):2095-101

9. Kurz SK, Rapp M, Steffens HP, Grzimek NK, Schmalz S, Reddehase MJ: Focal transcriptional activity of murine cytomegalovirus during latency in the lungs. Journal of Virology. 1999;73(1):482-94 
10. Kurz SK, Reddehase MJ: Patchwork pattern of transcriptional reactivation in the lungs indicates sequential checkpoints in the transition from murine cytomegalovirus latency to recurrence. Journal of Virology. 1999;73(10):8612-22

11. Kurz S, Steffens HP, Mayer A, Harris JR, Reddehase MJ: Latency versus persistence or intermittent recurrences: evidence for a latent state of murine cytomegalovirus in the lungs. Journal of Virology. 1997;71(4):2980-7

12. Simon CO, Holtappels R, Tervo HM, Bohm V, Daubner T, Oehrlein-Karpi SA et al.: CD8 T cells control cytomegalovirus latency by epitope-specific sensing of transcriptional reactivation. J Virol. 2006;80(21):10436-56

13. Fields BN, Knipe DM, Howley PM: Fields virology. Philadelphia, Wolters Kluwer Health/Lippincott Williams \& Wilkins, 2007.

14. Polic B, Hengel H, Krmpotic A, Trgovcich J, Pavic I, Luccaronin P et al.: Hierarchical and redundant lymphocyte subset control precludes cytomegalovirus replication during latent infection. Journal of Experimental Medicine. 1998;188(6):1047-54

15. Jonjic S, Mutter W, Weiland F, Reddehase MJ, Koszinowski UH: Site-restricted persistent cytomegalovirus infection after selective long-term depletion of CD4+ T lymphocytes. J. Exp. Med. 1989;169(4):1199-212

16. Lucin P, Pavic I, Polic B, Jonjic S, Koszinowski UH: Gamma interferon-dependent clearance of cytomegalovirus infection in salivary glands. Journal of Virology. 1992;66(4):1977-84

17. van Leeuwen EM, Remmerswaal EB, Vossen MT, Rowshani AT, Wertheim-van Dillen PM, van Lier RA et al.: Emergence of a CD4+CD28- granzyme B+, cytomegalovirus-specific $\mathrm{T}$ cell subset after recovery of primary cytomegalovirus infection. J Immunol. 2004;173(3):1834-41

18. Walton SM, Mandaric S, Torti N, Zimmermann A, Hengel H, Oxenius A: Absence of cross-presenting cells in the salivary gland and viral immune evasion confine cytomegalovirus immune control to effector CD4 T cells. PLoS Pathog. 2011;7(8):e1002214

19. Walter EA, Greenberg PD, Gilbert MJ, Finch RJ, Watanabe KS, Thomas ED et al.: Reconstitution of cellular immunity against cytomegalovirus in recipients of allogeneic bone marrow by transfer of T-cell clones from the donor.[see comment]. New England Journal of Medicine. 1995;333(16):1038-44

20. Snyder CM, Loewendorf A, Bonnett EL, Croft M, Benedict CA, Hill AB: CD4+ T cell help has an epitope-dependent impact on CD8+ T cell memory inflation during murine cytomegalovirus infection. J Immunol. 2009;183(6):3932-41

21. Walton SM, Torti N, Mandaric S, Oxenius A: T cell help permits memory CD8(+) T cell inflation during cytomegalovirus latency. Eur J Immunol. 2011

22. Reddehase MJ, Weiland F, Munch K, Jonjic S, Luske A, Koszinowski UH: Interstitial murine cytomegalovirus pneumonia after irradiation: characterization of cells that limit viral replication during established infection of the lungs. Journal of Virology. 1985;55(2):264-73

23. Mutter W, Reddehase MJ, Busch FW, Buhring HJ, Koszinowski UH: Failure in generating hemopoietic stem cells is the primary cause of death from cytomegalovirus disease in the immunocompromised host. J. Exp. Med. 1988;167(5):1645-58 
24. Riddell SR, Watanabe KS, Goodrich JM, Li CR, Agha ME, Greenberg PD: Restoration of viral immunity in immunodeficient humans by the adoptive transfer of T cell clones. Science. 1992;257(5067):238-41

25. Sylwester AW, Mitchell BL, Edgar JB, Taormina C, Pelte C, Ruchti F et al.: Broadly targeted human cytomegalovirus-specific CD4+ and CD8+ T cells dominate the memory compartments of exposed subjects. J Exp Med. 2005;202(5):673-85

26. Holtappels R, Pahl-Seibert MF, Thomas D, Reddehase MJ: Enrichment of immediate-early 1 ( $\mathrm{m} 123 / \mathrm{pp} 89)$ peptide-specific CD8 T cells in a pulmonary CD62L(lo) memory-effector cell pool during latent murine cytomegalovirus infection of the lungs. Journal of Virology. 2000;74(24):11495-503

27. Karrer U, Wagner M, Sierro S, Oxenius A, Hengel H, Dumrese T et al.: Expansion of protective CD8+ T-cell responses driven by recombinant cytomegaloviruses. Journal of Virology. 2004;78(5):2255-64

28. Karrer U, Sierro S, Wagner M, Oxenius A, Hengel H, Koszinowski UH et al.: Memory inflation: continuous accumulation of antiviral CD8+ T cells over time. $\mathrm{J}$ Immunol. 2003;170(4):2022-9

29. Komatsu H, Inui A, Sogo T, Fujisawa T, Nagasaka H, Nonoyama S et al.: Large scale analysis of pediatric antiviral CD8+ T cell populations reveals sustained, functional and mature responses. Immun Ageing. 2006;3:11

30. Munks MW, Cho KS, Pinto AK, Sierro S, Klenerman P, Hill AB: Four distinct patterns of memory CD8 $\mathrm{T}$ cell responses to chronic murine cytomegalovirus infection. J Immunol. 2006;177(1):450-8

31. Northfield J, Lucas M, Jones H, Young NT, Klenerman P: Does memory improve with age? CD85j (ILT-2/LIR-1) expression on CD8 T cells correlates with 'memory inflation' in human cytomegalovirus infection. Immunol Cell Biol. 2005;83(2):1828

32. Sierro S, Rothkopf R, Klenerman P: Evolution of diverse antiviral CD8+ T cell populations after murine cytomegalovirus infection. European Journal of Immunology. 2005;35(4):1113-23

33. Snyder CM, Cho KS, Morrison EL, van Dommelen S, Shellam GR, Hill AB: Memory Inflation During Chronic Viral Infection is Maintained by Continuous Production of Short-Lived Functional T Cells. Immunity. 2008;29 (4):650-9

34. Appay V, Dunbar PR, Callan M, Klenerman P, Gillespie GM, Papagno L et al.: Memory CD8+ T cells vary in differentiation phenotype in different persistent virus infections. Nat Med. 2002;8(4):379-85

35. Champagne P, Ogg GS, King AS, Knabenhans C, Ellefsen K, Nobile M et al.: Skewed maturation of memory HIV-specific CD8 T lymphocytes. Nature. 2001;410(6824):106-11

36. Gamadia LE, Rentenaar RJ, Baars PA, Remmerswaal EB, Surachno S, Weel JF et al.: Differentiation of cytomegalovirus-specific CD8(+) T cells in healthy and immunosuppressed virus carriers. Blood. 2001;98(3):754-61

37. Gamadia LE, van Leeuwen EM, Remmerswaal EB, Yong SL, Surachno S, Wertheim-van Dillen PM et al.: The size and phenotype of virus-specific T cell populations is determined by repetitive antigenic stimulation and environmental cytokines. J Immunol. 2004;172(10):6107-14 
38. Hertoghs KM, Moerland PD, van Stijn A, Remmerswaal EB, Yong SL, van de Berg

PJ et al.: Molecular profiling of cytomegalovirus-induced human CD8+ T cell differentiation. J Clin Invest. 2010

39. Kern F, Khatamzas E, Surel I, Frommel C, Reinke P, Waldrop SL et al.: Distribution of human CMV-specific memory T cells among the CD8pos. subsets defined by CD57, CD27, and CD45 isoforms. Eur J Immunol. 1999;29(9):2908-15

40. Makedonas G, Hutnick N, Haney D, Amick AC, Gardner J, Cosma G et al.: Perforin and IL-2 upregulation define qualitative differences among highly functional virus-specific human CD8 T cells. PLoS Pathog. 2010;6(3):e1000798

41. Miles DJ, van der Sande M, Jeffries D, Kaye S, Ismaili J, Ojuola O et al.: Cytomegalovirus infection in Gambian infants leads to profound CD8 T-cell differentiation. J Virol. 2007;81(11):5766-76

42. van Leeuwen EM, Gamadia LE, Baars PA, Remmerswaal EB, ten Berge IJ, van Lier RA: Proliferation requirements of cytomegalovirus-specific, effector-type human CD8+ T cells. J Immunol. 2002;169(10):5838-43

43. van Leeuwen EM, de Bree GJ, Remmerswaal EB, Yong SL, Tesselaar K, ten Berge IJ et al.: IL-7 receptor alpha chain expression distinguishes functional subsets of virus-specific human CD8+ T cells. Blood. 2005;106(6):2091-8

44. Wills MR, Okecha G, Weekes MP, Gandhi MK, Sissons PJ, Carmichael AJ: Identification of naive or antigen-experienced human CD8(+) T cells by expression of costimulation and chemokine receptors: analysis of the human cytomegalovirusspecific CD8(+) T cell response. J Immunol. 2002;168(11):5455-64

45. Wills MR, Carmichael AJ, Weekes MP, Mynard K, Okecha G, Hicks R et al.: Human virus-specific CD8+ CTL clones revert from CD45ROhigh to CD45RAhigh in vivo: CD45RAhighCD8+ T cells comprise both naive and memory cells. J Immunol. 1999;162(12):7080-7

46. Romero P, Zippelius A, Kurth I, Pittet MJ, Touvrey C, Iancu EM et al.: Four functionally distinct populations of human effector-memory CD8+ T lymphocytes. J Immunol. 2007;178(7):4112-9

47. Ibegbu CC, Xu YX, Harris W, Maggio D, Miller JD, Kourtis AP: Expression of killer cell lectin-like receptor G1 on antigen-specific human CD8+ T lymphocytes during active, latent, and resolved infection and its relation with CD57. J Immunol. 2005;174(10):6088-94

48. Thimme R, Appay V, Koschella M, Panther E, Roth E, Hislop AD et al.: Increased expression of the NK cell receptor KLRG1 by virus-specific CD8 T cells during persistent antigen stimulation. J Virol. 2005;79(18):12112-6

49. Wang EC, Moss PA, Frodsham P, Lehner PJ, Bell JI, Borysiewicz LK: CD8highCD57+ T lymphocytes in normal, healthy individuals are oligoclonal and respond to human cytomegalovirus. J Immunol. 1995;155(10):5046-56

50. Weekes MP, Wills MR, Mynard K, Hicks R, Sissons JG, Carmichael AJ: Large clonal expansions of human virus-specific memory cytotoxic T lymphocytes within the CD57+CD28- CD8+ T-cell population. Immunology. 1999;98(3):443-9

51. Masopust D, Ha SJ, Vezys V, Ahmed R: Stimulation history dictates memory CD8 T cell phenotype: implications for prime-boost vaccination. J Immunol. 2006;177(2):831-9 
52. Sarkar S, Kalia V, Haining WN, Konieczny BT, Subramaniam S, Ahmed R:

Functional and genomic profiling of effector CD8 T cell subsets with distinct memory fates. J Exp Med. 2008;205(3):625-40

53. Brenchley JM, Karandikar NJ, Betts MR, Ambrozak DR, Hill BJ, Crotty LE et al.: Expression of CD57 defines replicative senescence and antigen-induced apoptotic death of CD8+ T cells. Blood. 2003;101(7):2711-20

54. Ouyang Q, Wagner WM, Wikby A, Walter S, Aubert G, Dodi AI et al.: Large numbers of dysfunctional CD8+ T lymphocytes bearing receptors for a single dominant CMV epitope in the very old. J Clin Immunol. 2003;23(4):247-57

55. Voehringer D, Blaser C, Brawand P, Raulet DH, Hanke T, Pircher H: Viral infections induce abundant numbers of senescent CD8 T cells. J Immunol. 2001;167(9):4838-43

56. Voehringer D, Koschella M, Pircher H: Lack of proliferative capacity of human effector and memory $\mathrm{T}$ cells expressing killer cell lectinlike receptor G1 (KLRG1). Blood. 2002;100(10):3698-702

57. Doisne JM, Urrutia A, Lacabaratz-Porret C, Goujard C, Meyer L, Chaix ML et al.: CD8+ T cells specific for EBV, cytomegalovirus, and influenza virus are activated during primary HIV infection. J Immunol. 2004;173(4):2410-8

58. Marchant A, Appay V, Van Der Sande M, Dulphy N, Liesnard C, Kidd M et al.: Mature CD8(+) T lymphocyte response to viral infection during fetal life. J Clin Invest. 2003;111(11):1747-55

59. Waller EC, McKinney N, Hicks R, Carmichael AJ, Sissons JG, Wills MR: Differential costimulation through CD137 (4 1BB) restores proliferation of human virus-specific "effector memory" (CD28 CD45RAHI) CD8+ T cells. Blood. 2007;110(13):4360-6

60. Munks MW, Gold MC, Zajac AL, Doom CM, Morello CS, Spector DH et al.: Genome-wide analysis reveals a highly diverse CD8 T cell response to murine cytomegalovirus. J Immunol. 2006;176(6):3760-6

61. Hutchinson S, Sims S, O'Hara G, Silk J, Gileadi U, Cerundolo V et al.: A dominant role for the immunoproteasome in $\mathrm{CD} 8 \mathrm{~T}$ cell responses to murine cytomegalovirus. PLoS One. 2011;6(2):e14646

62. Scheinberg P, Melenhorst JJ, Brenchley JM, Hill BJ, Hensel NF, Chattopadhyay PK et al.: The transfer of adaptive immunity to cytomegalovirus (CMV) during hematopoietic stem cell transplantation is dependent on the specificity and phenotype of CMV-specific T cells in the donor. Blood. 2009

63. Iancu EM, Corthesy P, Baumgaertner P, Devevre E, Voelter V, Romero P et al.: Clonotype selection and composition of human CD8 T cells specific for persistent herpes viruses varies with differentiation but is stable over time. $\mathbf{J}$ Immunol. 2009;183(1):319-31

64. van Leeuwen EM, ten Berge IJ, van Lier RA: Induction and maintenance of CD8+ T cells specific for persistent viruses. Adv Exp Med Biol. 2007;590:121-37

65. Day EK, Carmichael AJ, ten Berge IJ, Waller EC, Sissons JG, Wills MR: Rapid CD8+ T cell repertoire focusing and selection of high-affinity clones into memory following primary infection with a persistent human virus: human cytomegalovirus. J Immunol. 2007;179(5):3203-13 
66. Joshi NS, Cui W, Chandele A, Lee HK, Urso DR, Hagman J et al.: Inflammation directs memory precursor and short-lived effector CD8(+) T cell fates via the graded expression of T-bet transcription factor. Immunity. 2007;27(2):281-95

67. Libri V, Azevedo RI, Jackson SE, Di Mitri D, Lachmann R, Fuhrmann S et al.: Cytomegalovirus infection induces the accumulation of short-lived, multifunctional CD4+ CD45RA+ CD27 T cells: the potential involvement of interleukin-7 in this process. Immunology. 2011;132(3):326-39

68. Kemball CC, Lee ED, Vezys V, Pearson TC, Larsen CP, Lukacher AE: Late priming and variability of epitope-specific CD8+ T cell responses during a persistent virus infection. J Immunol. 2005;174(12):7950-60

69. Vezys V, Masopust D, Kemball CC, Barber DL, O'Mara LA, Larsen CP et al.: Continuous recruitment of naive $\mathrm{T}$ cells contributes to heterogeneity of antiviral CD8 T cells during persistent infection. J Exp Med. 2006;203(10):2263-9

70. Leen AM, Heslop HE: Cytotoxic T lymphocytes as immune-therapy in haematological practice. Br J Haematol. 2008;143(2):169-79

71. Berger C, Jensen MC, Lansdorp PM, Gough M, Elliott C, Riddell SR: Adoptive transfer of effector CD8+ T cells derived from central memory cells establishes persistent T cell memory in primates. J Clin Invest. 2008;118(1):294-305

72. Wherry EJ: T cell exhaustion. Nat Immunol. 2011;12(6):492-9

73. Sester U, Presser D, Dirks J, Gartner BC, Kohler H, Sester M: PD-1 Expression and IL-2 Loss of Cytomegalovirus- Specific T Cells Correlates with Viremia and Reversible Functional Anergy. Am J Transplant. 2008

74. La Rosa C, Krishnan A, Longmate J, Martinez J, Manchanda P, Lacey SF et al.: Programmed Death-1 Expression in Liver Transplant Recipients as a Prognostic Indicator of Cytomegalovirus Disease. J Infect Dis. 2008;197(1):25-33

75. Wherry EJ, Ha SJ, Kaech SM, Haining WN, Sarkar S, Kalia V et al.: Molecular signature of CD8+ T cell exhaustion during chronic viral infection. Immunity. 2007;27(4):670-84

76. Wherry EJ, Ahmed R: Memory CD8 T-cell differentiation during viral infection. J Virol. 2004;78(11):5535-45

77. Zajac AJ, Blattman JN, Murali-Krishna K, Sourdive DJ, Suresh M, Altman JD et al.: Viral immune evasion due to persistence of activated $\mathrm{T}$ cells without effector function. J Exp Med. 1998;188(12):2205-13

78. Shin H, Blackburn SD, Blattman JN, Wherry EJ: Viral antigen and extensive division maintain virus-specific CD8 T cells during chronic infection. J Exp Med. 2007;204(4):941-9

79. Reddehase MJ, Balthesen M, Rapp M, Jonjic S, Pavic I, Koszinowski UH: The conditions of primary infection define the load of latent viral genome in organs and the risk of recurrent cytomegalovirus disease. J. Exp. Med. 1994;179(1):185-93

80. Seckert CK, Schader SI, Ebert S, Thomas D, Freitag K, Renzaho A et al.: Antigenpresenting cells of haematopoietic origin prime cytomegalovirus-specific CD8 Tcells but are not sufficient for driving memory inflation during viral latency. J Gen Virol. 2011;92(Pt 9):1994-2005

81. Torti N, Walton SM, Murphy KM, Oxenius A: Batf3 transcription factor-dependent DC subsets in murine CMV infection: differential impact on T cell priming and memory inflation. Eur J Immunol. 2011 


\section{Figure Legends:}

3 Fig. 1 Antigen-specific T cells with an effector- or memory-phenotype develop

4 during MCMV infection in C57BL/6 mice. a) Schematic of the kinetics of CD8+ T

5 cells specific for 5 different MCMV antigens. b) Representative FACS plots of

6 inflationary and non-inflationary T cells in the blood, spleen and bone marrow of

7 mice infected for 19 weeks with MCMV. The data show the expression of CD127

8 (IL-7R $\alpha$ ) and KLRG-1 for all CD8+ T cells (left most panels) or CD8+ T cells that

9 also bound to MHC-tetramers loaded with the indicated peptides. All FACS plots

10 were taken from a single animal for comparison. c) Average ( $n=5$ mice)

11 frequency of CD127 $7^{\text {hi }}, \mathrm{KLRG}-1^{\text {neg }}$, memory-phenotype $\mathrm{T}$ cells specific for each of

12 the indicated antigens. Data were derived from the upper left quadrants of the

13 FACS plots gated as shown in b. p-values were derived from a student's t-test for 14 paired data.

16 Fig. 2 Two proposed models to explain the persistence of MCMV-specific CD8+

17 T cells during memory inflation. The schematic on the left describes cells that are

18 long-lived or self-sustaining. The schematic on the right describes a situation in

19 which inflationary $T$ cells are repeatedly replenished by clonal expansions,

20 perhaps from a small memory-like pool of cells specific for the same peptides. In

21 this model, a dominant T cell clone (represented by the light colored expansions)

22 is selected to undergo clonal expansion more frequently. Such clonal dominance

23 could be explained by an increased number of cells within this clone, or perhaps

24 a "better fit" $T$ cell receptor. When sub-dominant clones are stimulated, the 
1 composition of the inflationary pool is predicted to change (indicated by the

2 dotted lines).

4 Fig. 3 Buffered memory: A model to explain the persistence of functional

5 memory during chronic CMV infection. In this model, a large number of effector-

6 phenotype T cells traffic to and accumulate in non-lymphoid organs, where the

7 majority of latent virus resides. These cells control most viral reactivation,

8 typically prior to virion production, and prevent memory-like T cells from

9 experiencing antigen stimulation. Occasional antigen "leaks" or expression of

10 viral antigens in a specific cell type or organ, might lead to stimulation of

11 memory-like cells (indicated by the down-facing arrow) and new clonal

12 expansions (upward, curved arrow) that produce large numbers of effector-

13 phenotype T cells to join the pool of effector cells in the periphery. 